\title{
The Methylazoxymethanol Acetate (MAM-E 17) Rat Model: Molecular and Functional Effects in the Hippocampus
}

\author{
Eva Hradetzky 1,2, Thomas M Sanderson ${ }^{2}$, Tsz M Tsang ${ }^{3}$, John L Sherwood ${ }^{2}$, Stephen M Fitzjohn ${ }^{2}$, \\ Viktor Lakics', Nadia Malik', Stephanie Schoeffmann', Michael J O'Neill', Tammy MK Cheng', \\ Laura W Harris', Hassan Rahmoune', Paul C Guest', Emanuele Sher', Graham L Collingridge ${ }^{4}$, \\ Elaine Holmes ${ }^{3}$, Mark D Tricklebank ${ }^{*, 2}$ and Sabine Bahn*,1,5
}

'Department of Chemical Engineering and Biotechnology, University of Cambridge, Cambridge, UK; ${ }^{2}$ Lilly Centre for Cognitive Neuroscience, Eli Lilly \& Co. Ltd, Windlesham, Surrey, UK; ${ }^{3}$ Faculty of Medicine, Division of Surgery, Oncology, Reproductive Biology and Anesthetics, Department of Biomolecular Medicine, Imperial College, London, UK; ${ }^{4}$ MRC Centre for Synaptic Plasticity, Department of Anatomy, School of Medical Sciences, University of Bristol, Bristol, UK; ${ }^{5}$ Department of Neuroscience, Erasmus University Medical Centre, Rotterdam, The Netherlands

\begin{abstract}
Administration of the DNA-alkylating agent methylazoxymethanol acetate (MAM) on embryonic day 17 (E 17) produces behavioral and anatomical brain abnormalities, which model some aspects of schizophrenia. This has lead to the premise that MAM rats are a neurodevelopmental model for schizophrenia. However, the underlying molecular pathways affected in this model have not been elucidated. In this study, we investigated the molecular phenotype of adult MAM rats by focusing on the frontal cortex and hippocampal areas, as these are known to be affected in schizophrenia. Proteomic and metabonomic analyses showed that the MAM treatment on El7 resulted primarily in deficits in hippocampal glutamatergic neurotransmission, as seen in some schizophrenia patients. Most importantly, these results were consistent with our finding of functional deficits in glutamatergic neurotransmission, as identified using electrophysiological recordings. Thus, this study provides the first molecular evidence, combined with functional validation, that the MAM-E 17 rat model reproduces hippocampal deficits relevant to the pathology of schizophrenia.

Neuropsychopharmacology (2012) 37, 364-377; doi: 10.1038/npp.201 1.219; published online 28 September 201 I
\end{abstract}

Keywords: animal models; schizophrenia; methylazoxymethanol acetate; hippocampus; electrophysiology; mass spectrometry

\section{INTRODUCTION}

Administration of the short-acting DNA-alkylating agent methylazoxymethanol acetate (MAM; Cattabeni and Di Luca, 1997; Cattaneo et al, 1995; Meyn and Murray, 1984) on embryonic day 17 (E17) to rat dams interferes with the development of specific brain regions in the offspring (Bayer et al, 1993; Moore et al, 2006). Through selective disturbance of proliferation and migration of neuronal precursor cells undergoing their final mitosis, MAM induces morphological and cytological alterations modeling phenomena seen in schizophrenia post-mortem brains (for review see Lodge and Grace, 2009b). Behavioral studies of

*Correspondence: Dr MD Tricklebank, Lilly Centre for Cognitive Neuroscience, Eli Lilly \& Co. Ltd, Erl Wood Manor, Windlesham, Surrey, UK, Tel: + 44 (0) 1276-483000, Fax: + 44 (0) 1276-484921, E-mail: tricklebank_mark@lilly.com or Dr S Bahn, Department of Chemical Engineering and Biotechnology, University of Cambridge, Tennis Court Road, Cambridge, Cambridgeshire CB2 IQT, UK, Tel: + 44 (0) I223 334I5I, Fax: + 44 (0) I223 334I62,

E-mail: sb209@cam.ac.uk

Received 8 June 2011; revised 15 August 2011; accepted 19 August 2011 offspring of MAM-treated rats (hereafter referred to as MAM rats) showed deficits in sensorimotor gating (Le Pen et al, 2006), an inability to ignore irrelevant stimuli (Flagstad et al, 2005), hypersensitivity to amphetamine and $\mathrm{N}$-methyl-D-aspartate (NMDA) receptor antagonists (Penschuck et al, 2006), and social withdrawal (Flagstad et al, 2004) with onset in adolescence (Le Pen et al, 2006). Although direct evaluation of schizophrenia symptoms in animal models is inherently difficult, such effects have been related to neuropsychiatric deficits seen in schizophrenia (Braff et al, 1992; Hansen et al, 2009; Laruelle et al, 1996; Lubow and Gewirtz, 1995). Consequently, the MAME17 rat model is widely thought to represent a neurodevelopmental model of schizophrenia (Lodge and Grace, 2009b).

Utilization of any model for investigation of pathological mechanisms and novel drug discovery requires identification of which molecular components of a disease can be represented. Apart from studies which have used immunohistochemical staining for parvalbumin and reelin in the frontal cortex and hippocampus (Lodge et al, 2009a; Matricon et al, 2010; Penschuck et al, 2006), molecular characterization of the MAM-E17 rat model has not yet 
been reported. As most post-mortem and in vivo studies of schizophrenia patients have identified deficits in the prefrontal cortex and hippocampus (Bertolino et al, 1996; Harrison, 1999; Tsai et al, 1995), we have attempted to identify expression differences in the proteome and metabonome of the equivalent brain regions in MAM rats. Furthermore, we evaluated if the identified molecular changes translate into synaptic physiology. Such analyses may provide molecular and physiological correlates for some of the histological and behavioral deficits seen in MAM rats. The relevance of these findings to schizophrenia is discussed.

\section{MATERIALS AND METHODS}

\section{Animals}

All procedures were conducted in full compliance with the Home Office Guidance (UK Animals Scientific Procedures Act 1986) and the ethical policies of Eli Lilly \& Co. Sprague Dawley rat dams (Charles River, Margate, UK) were injected intraperitoneally with either $22 \mathrm{mg} / \mathrm{kg}$ MAM $(26 \mathrm{mg} / \mathrm{ml}$ concentration accounting for liquid density) or vehicle sham $(0.9 \%$ saline $)$ on gestational day 17 . For proteomic and metabonomic experiments, rats were killed at 3 months by cervical dislocation. Brains were dissected on ice, frozen in liquid nitrogen and stored at $-80^{\circ} \mathrm{C}$ until use. For electrophysiological recordings, samples were prepared as described below.

\section{Tissue Fractionation}

Frontal cortex and hippocampal tissues from 10 MAM and 10 sham rats were homogenized. For quality control purposes, control rat frontal cortex and hippocampus samples were homogenized, split into five aliquots and prepared in parallel with the MAM and sham samples. Two fractions were produced using the ProteoExtract Subcellular Proteome Extraction Kit (Calbiochem, Darmstadt, Germany). Both fractions were stored at $-80^{\circ} \mathrm{C}$ until use. In an independent experiment, a frontal cortex homogenate was split into 12 aliquots, fractionated as above, and the resulting samples (fraction 2) were divided randomly into two groups of six for method validation. Each group was spiked with four non-homologous proteins (porcine albumin, bovine asialofetuine, bovine casein- $\beta$, and human lactogen) at the indicated concentrations (Figure 1a).

\section{Liquid Chromatography}

Proteins in fractions 1 and $2(200 \mu \mathrm{g}$ each) were precipitated using the ProteoExtract Precipitation Kit (Calbiochem). The resulting pellets were digested using the ProteoExtract Allin-one Trypsin Digestion Kit (Calbiochem). All further analyses were carried out in triplicate. Separation of the resulting peptides was achieved using a reverse-phase C18 column (inner diameter $=75 \mu \mathrm{m}$, length $=200 \mathrm{~mm}$, particle size $=1.7 \mu \mathrm{m}$; Waters Corporation, Milford, MA) on a nano Acquity system (Waters Corporation). Buffer A consisted of $0.1 \%$ formic acid in water, and buffer $B$ was $0.1 \%$ formic acid in acetonitrile. The peptides were separated at a

\begin{tabular}{lccccc} 
a PROTEIN & \multicolumn{2}{c}{$\begin{array}{c}\text { Spiked } \\
\text { concetration } \\
\text { group A }\end{array}$} & $\begin{array}{c}\text { Ratio } \\
\text { group B }\end{array}$ & $\begin{array}{c}\text { Ratio } \\
\text { expected }\end{array}$ & $\begin{array}{c}\text { Deviation } \\
\text { measured }\end{array}$ \\
\hline of ratio
\end{tabular}

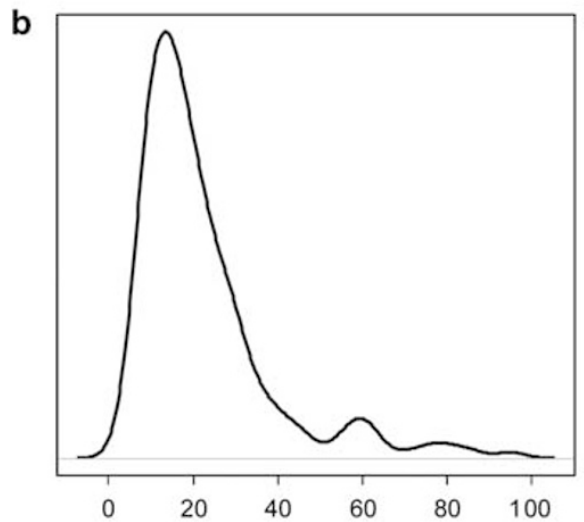

Relative standard deviation of protein measurement (\%)

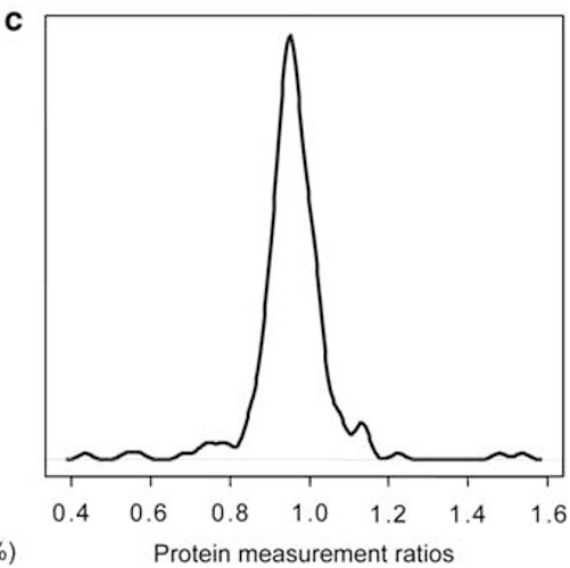

Figure I Technical validation of LC-MS ${ }^{E}$ proteomics using 12 spiked replicates of rat brain lysates. (a) Accuracy was assessed by measurement of four

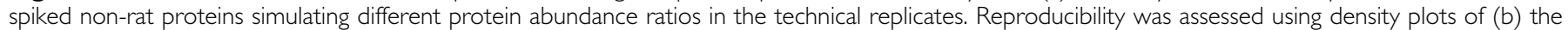
RSD of the protein abundance measurements of 189 rat proteins in each technical replicate and $(c)$ the relative protein abundance (ideal value $=1$ ). 
flow rate of $0.3 \mu \mathrm{l} / \mathrm{min}$ using the following gradients: 0-90 min, 3-30\% B; 90-115 min, 30-90\% B; 115-125 min, 90\% B; $125-126 \mathrm{~min}, 90-3 \% \mathrm{~B}$; and $126-150 \mathrm{~min}, 3 \% \mathrm{~B}$.

\section{Mass Spectrometry}

Eluting peptides were ionized at the electrospray interface and analyzed in positive ion mode using a Q-TOF Premier mass spectrometer (Waters Corporation), operated in alternate scanning data-independent acquisition configuration for label-free peptide quantification and identification $\left(\mathrm{MS}^{\mathrm{E}}\right.$; Silva et al, 2005). Precursor ion (MS, 0.6 s) and fragment ion $\left(\mathrm{MS}^{\mathrm{E}}, 0.6 \mathrm{~s}\right)$ spectra were acquired continuously. External reference spectra of [Glu1]-fibrinopeptide B were recorded every $30 \mathrm{~s}$ for mass correction.

\section{Data Processing and Protein Identification}

The data generated were processed and queried against the rat portion of the SwissProt database (release 55.6, 200806), using ProteinLynx Global Server v2.3 (Waters Corporation) as described (Geromanos et al, 2009; Li et al, 2009). Data filtering for peptides was performed using the free statistical software package $\mathrm{R}$ (http://cran.r-project.org). The filtering criteria required that peptides were (i) identified by database searching, (ii) present in at least two of the three liquid chromatography mass spectrometry in expression mode (LC-MS ${ }^{\mathrm{E}}$ ) replicates, and (iii) present in at least $80 \%$ of the samples of each treatment group. Quantitative peptide measurements for each replicate were normalized against the total ion volume of all de-convoluted spectra. Replicates were averaged and ratios of protein abundance for each protein were calculated based on the sum of peptides. Significance of protein expression differences was determined using Student's $t$-test with Welch's correction $(p<0.05)$. False discovery rate (FDR) was used to control for multiple hypothesis testing $(q<0.5$; Benjamini and Hochberg, 1995; Storey, 2002).

\section{In Silico Pathway Analysis}

The most significant molecular functions, canonical pathways, and interactions represented by the integrated lists of significantly altered proteins or metabolites in the MAME17 rat model were determined in silico using the Ingenuity Pathway Analysis Knowledge Base (IPKB; Ingenuity Systems, http://www.ingenuity.com; Calvano et al, 2005). The IPKB contains molecular information available in the scientific literature. Lists of the significantly altered proteins or metabolites found in the MAM-E17 rat model were uploaded to the IPKB software (inclusion criterion for proteins: $p<0.05, q<0.05$, and metabolites: $p<0.05)$.

The functional and pathway analysis identified the biological functions that were most significant to the data set by overlaying the significantly altered molecules (inclusion criterion for proteins: $p<0.05, q<0.05$, and metabolites: $p<0.05$ ) onto predefined maps containing functional and pathway information of the IPKB database. Right-tailed Fisher's exact test was used to calculate a $p$-value determining the probability that each biological function or pathway assigned to that data set is due to chance alone. Furthermore, network analysis of significantly altered proteins $(p<0.05, q<0.05)$ was performed. Proteins were mapped to their corresponding objects in the IPKB. Networks were then generated algorithmically on the basis of the connectivity derived from molecular interaction information.

\section{Targeted Analyte Cluster Analysis}

Complementary to the in silico pathway analysis, we applied the targeted analyte cluster (TAC) algorithm, as described previously by Cheng et al (2010), as a means of identifying significantly affected pathways. Significantly changed proteins $(p<0.05, q<0.5)$ identified by LC-MS ${ }^{\mathrm{E}}$ screening of the MAM-E17 model were subjected to TAC analysis. This method identifies clusters of 2-4 molecules with correlated expression levels, which account for the main variance in the data. This is likely to occur for coordinately regulated molecules, such as those that are components of the same molecular complexes or pathways.

At the statistical level, data points that are not linearly separable in a two-dimensional (2D) space can be linearly separated in a higher dimensional (3D) space. TAC applies factor analysis to identify molecules with linear combinations of molecular expression levels, which are the most effective representation of the total variable space of the data set. On the basis of the representative molecules identified, the prediction power of the molecular combinations can then be evaluated by testing other data sets using kernel principal component analysis (kPCA). For each prediction, no more than 2-4 molecules are tested to avoid over-fitting in cases of small sample sizes. For example, if a specific combination of proteins $A, B$, and $C$ gives a good separation of MAM and sham rat samples on $2 \mathrm{D}$ (planar) projections of $\mathrm{kPCA}$, then the protein cluster comprised of $\mathrm{A}, \mathrm{B}$, and $\mathrm{C}$ is likely to be an effective marker for identifying MAM rats. Half of the MAM-E17 and sham rats were selected randomly as a training set. The trained model was applied to predict correct assignment as a MAM or sham rat from the remaining half. The training and prediction procedure was repeated 1000 times. The precision of each protein cluster was calculated finally as the average precision of the 1000 iterations. Precision was defined as the percentage of MAM rats projected correctly.

\section{Immunoblot Analysis}

Relative differences in abundance of the most significant proteins found using $\mathrm{LC}-\mathrm{MS}^{\mathrm{E}}$ profiling were tested by immunoblot analysis. Samples of fractions 1 and $2(10 \mu \mathrm{g}$ protein) from the same MAM $(n=8)$ and sham $(n=8)$ hippocampal extracts, used previously for LC-MS ${ }^{\mathrm{E}}$ analysis, were loaded onto $4-12 \%$ NuPAGE Novex Bis-Tris gels (Invitrogen, Paisley, UK) to separate the proteins by electrophoresis. The proteins were then transferred electrophoretically onto polyvinylidene fluoride membranes. Membranes were blocked, incubated with primary and secondary antibodies and then scanned with the Odyssey Infrared Imaging System following the provided protocol (LI-COR Bioscience; Lincoln, NE). The following primary antibodies were used (all from Abcam, Cambridge, UK; dilution indicated in parentheses): rabbit antiAMPA1 (alpha-amino-3-hydroxy-5-methyl-4-isoxazolepropionic 
acid; $1: 200)$, mouse anti-ARP3 (1:10000), rabbit antiGAPDH $(1: 1000)$, mouse anti-GAPDH $(1: 1000)$, rabbit anti-HPCA $(1: 400)$, rabbit anti-MARCKS $(1: 5000)$, rabbit anti-PMCA1 (1:500), and rabbit anti-SYNJ1 (1:300). In addition, the following secondary antibodies were used (LI-COR Bioscience): donkey anti-mouse IRDye800CW and donkey anti-rabbit IRDye680 (both 1:15000). Quantification of the infrared signals was performed with the analysis software provided. For normalization of the protein signals, GAPDH was used as a loading control. Only scanned blots with a relative standard deviation of less than $30 \%$ for the GAPDH signal were considered. The significance of protein band expression differences was determined using $t$-test statistics with Welch's correction $(p<0.05)$.

To identify the unpredicted band in the AMPA1 immunoblot of fraction 2, a pooled sample of fraction 2 was split into two aliquots. One aliquot was treated with $\lambda$ protein phosphatase, following the protocol provided (New England Biolabs, Ipswich, MA). Proteins of both aliquots were subjected to immunoblot analysis and probed with phospho-specific rabbit anti-phosphoSerin-845 and rabbit anti-phosphoSerin-831 AMPA1 antibodies (Abnova, Taipei City, Taiwan; both $1: 1000)$ as described above.

\section{${ }^{1}$ H-Nuclear Magnetic Resonance Spectroscopy Analysis}

Striatum $(20 \mathrm{mg})$, hippocampus $(20 \mathrm{mg})$, frontal cortex (30 mg), and cerebellum (65 mg) of 10 MAM and 10 sham samples were homogenized in 1-ml acetonitrile/deionised water $(1: 1)$. The homogenates were combined with an equal volume of $3: 1$ chloroform/methanol, forming aqueous and lipid phases. The phases were vortexed to homogeneity and centrifuged for $7 \mathrm{~min}$ at $1200 \mathrm{~g}$ at $5^{\circ} \mathrm{C}$. The aqueous phase was collected, left overnight at room temperature to remove residual acetonitrile by air drying and then freeze-dried at $-70^{\circ} \mathrm{C}$. The samples were reconstituted in $600 \mu \mathrm{l}$ of deuterium oxide. For each sample, a ${ }^{1} \mathrm{H}$-nuclear magnetic resonance spectroscopy (NMR) spectrum was acquired at $600.13 \mathrm{MHz}$ on a Bruker DRX-600 spectrometer (Bruker $\mathrm{GmBH}$ ) using the first increment of the nuclear overhauser effect spectroscopy pulse sequence (relaxation delay, $\pi / 2-t 1-\pi / 2-t \mathrm{~m}-\pi / 2$; repetition time) as described previously (Lan et al, 2009). For each spectrum, 256 transients were acquired to yield 32000 data points, with a spectral width of $10 \mathrm{kHz}$ at an ambient probe temperature of $25^{\circ} \mathrm{C}$. The resulting free induction decays were multiplied by an exponential weight function corresponding to a line broadening of $0.3 \mathrm{~Hz}$, prior to Fourier transformation. Complete spectra in the chemical shift range $0.20-10$ p.p.m. (parts per million) were phased, baseline corrected, and calibrated according to the reference resonance at 1.33 p.p.m. (lactate doublet), using the Topspin v2.0 software (Bruker $\mathrm{GmBH}$ ). Spectral variation effects due to presaturation of water were removed by zeroing intensity values between 4.5 and 4.9 p.p.m. To identify metabolites that differentiate MAM from sham animals, partial least squares discriminate analysis (PLS-DA) was performed on full-resolution ${ }^{1} \mathrm{H}$ NMR spectral data using SIMCA-P v12 (Umetrics AB, Umeå, Sweden). To remove confounding variations, orthogonal projection on latent structures discriminant analyses (OPLS-DA) of full-resolution spectra was conducted as described previously (Cloarec et al, 2005). This method is an improvement compared with the traditional supervised algorithm of PLS, and enhances the interpretability of spectral variation between classes (Eriksson et al, 2004; Lan et al, 2009). To confirm the differences identified by multivariate testing, univariate analyses on manually integrated single resonance groups were performed (Student's $t$-test, $p<0.05)$. Pathways and functions associated with significantly altered metabolites were determined using in silico pathway analysis, as described above.

\section{Electrophysiological Recordings}

Electrophysiological recordings were made from transverse dorsal hippocampal slices $(400 \mu \mathrm{m})$ prepared from 3 - to 4-month-old MAM and sham rats. The experimenter was blind to the treatment group. Animals were anesthetized using isofluorane and killed by cervical dislocation. Brains were removed and placed in ice-cold artificial cerebrospinal fluid (aCSF; $124 \mathrm{mM} \mathrm{NaCl}, 3 \mathrm{mM} \mathrm{KCl}, 26 \mathrm{mM} \mathrm{NaHCO}_{3}$, $1.25 \mathrm{mM} \mathrm{NaH}_{2} \mathrm{PO}_{4}, 10 \mathrm{mM} \mathrm{MgSO}_{4}, 10 \mathrm{mM}$ glucose, $1 \mathrm{mM}$ $\mathrm{CaCl}_{2}$ ) aerated with $95 \% \mathrm{O}_{2}$ and $5 \% \mathrm{CO}_{2}$. Hippocampi were removed, sliced and maintained at $5^{\circ} \mathrm{C}$ in a $765-1$ temperature-controlled chamber. The cornu ammonis 3 of hippocampus region was removed and the slices were transferred to aCSF containing $1 \mathrm{mM} \mathrm{MgSO}_{4}$ and $2 \mathrm{mM}$ $\mathrm{CaCl}_{2}$. Slices were incubated at $32^{\circ} \mathrm{C}$ for $30 \mathrm{~min}$ to stimulate metabolism and then maintained at room temperature for at least $1 \mathrm{~h}$ before recordings were made.

Extracellular recordings were made in a Slicemate submerged chamber (Scientifica, Bedford, UK) maintained at $32^{\circ} \mathrm{C}$ and continuously perfused at $2 \mathrm{ml} / \mathrm{min}$ with aCSF modified to contain $1 \mathrm{mM} \mathrm{MgSO}$ and $2 \mathrm{mM} \mathrm{CaCl}_{2}$, and aerated as above. Standard extracellular recording techniques were used to measure the slope of field excitatory post-synaptic potentials (fEPSPs) from stratum radiatum in area CA1 (cornu ammonis 1 of hippocampus), evoked by stimulation of the Schaffer collateral by current injection using a concentric bipolar electrode. Recordings were made with an Axopatch 200B amplifier (Molecular devices, Silicon Valley, CA), filtered at $2 \mathrm{kHz}$, and digitized using a Digidata $1322 \mathrm{~A} \mathrm{~A} / \mathrm{D}$ board at a sampling rate of $10 \mathrm{kHz}$. In pharmacological experiments using GYKI53784, recordings were filtered at $10 \mathrm{kHz}$ and digitized at $40 \mathrm{kHz}$, followed by post-filtering with a digital gaussian filter to an effective cutoff frequency of $1 \mathrm{kHz}$. Recordings were monitored and analyzed online and reanalyzed offline using WinLTP (Anderson and Collingridge, 2001). Pharmacological studies were performed to confirm the type of glutamate receptor responsible for synaptic transmission. Baseline responses were set at $5-10 \%$ of the maximal fEPSP obtained at $300 \mu \mathrm{A}$ stimulation. Following a stable baseline period of at least $20 \mathrm{~min}, 10 \mu \mathrm{M}$ GYKI53784 $(n=5$ and $n=5$ for MAM and sham rats, respectively) and $50 \mu \mathrm{M} 2$-amino-5-phosphonopentanoic acid (AP5; $n=9$ and $n=10$ for MAM and sham rats, respectively) were applied in the bath solution for $20 \mathrm{~min}$. To investigate the efficiency of synaptic transmission, 19 MAM slices and 11 sham slices from two batches were stimulated at a range of intensities that resulted in comparable fiber volley (FV) amplitudes. Four recordings were made at each stimulation strength at $0.033 \mathrm{~Hz}$ and the recordings were averaged. fEPSPs were related to the FV rather than the stimulation strength. This was carried out as 
the FV is a measure of the action potentials generated in the Schaffer collateral by the stimulating electrode, and is therefore the most direct input to synapses in area CA1. Linear regression was performed on the data produced using Prism software v5 (GraphPad). Data are presented as mean \pm SEM. Significant differences between MAM and sham samples were assessed using paired Student's $t$-tests in the pharmacological experiments and an unpaired Student's t-test in the comparison of the slopes of the input-output relationships between groups $(p<0.05)$.

\section{RESULTS}

\section{Technical Validation of LC-MS ${ }^{\mathrm{E}}$ Brain Tissue Proteomics}

The variation introduced by sample preparation and analysis can have a significant impact on the reliability of quantitative molecular profiling experiments. Protein quantification using LC-MS-based approaches has been challenged by physicochemical effects, which can obscure the linear relationship between the signal and abundance of an analyte (King et al, 2000). This is especially the case for complex samples such as tissue lysates. Therefore, we assessed the reproducibility and accuracy of the tissue extraction and $\mathrm{LC}-\mathrm{MS}^{\mathrm{E}}$ procedure in a validation experiment. A homogenized rat cortex sample was divided into 12 aliquots to generate technical replicates. After fractionation, the technical replicates were split into two equal groups (A and $B$ ) and spiked with non-rat proteins. Figure 1a shows the concentrations of the spiked proteins in both groups, simulating differential protein abundances between them. All 12 technical replicates were analyzed using LC-MS ${ }^{\mathrm{E}}$. To assess the reproducibility, the relative standard deviations (RSDs) and abundance ratios for 198 identified rat proteins were calculated and plotted (Figure $1 \mathrm{~b}$ and $\mathrm{c}$ ). Figure $1 \mathrm{~b}$ shows that the original protein abundance in the technical replicates deviated by $22 \%$ on average, due to sample preparation and analysis. We found in a previous study that $\sim 10 \%$ of the technical variation was introduced by the LC-MS ${ }^{\mathrm{E}}$ analysis method (data not shown). This is comparable to or better than other proteomics methods, which show an average variation of $19-30 \%$ from the analysis phase alone (Molloy et al, 2003; Molloy et al, 2005). In addition, the protein abundance ratio distribution in Figure 1c illustrates that the relative protein measurements differed by only $4 \%$ from the ideal ratio of 1 . Comparison of the simulated and measured fold changes of the four spiked non-rat proteins showed that the average deviation of the simulated expression difference was 20\% (Figure 1a). The values for the individual proteins vary possibly due to different physicochemical properties of the proteins, resulting in different ionization efficiencies (King et al, 2000). We also obtained a similar result using 20 aliquots of serum samples, which required fewer sample preparation steps (Levin et al, 2007). Consequently, the data showed that the integration of quality controls for $\mathrm{LC}_{-} \mathrm{MS}^{\mathrm{E}}$ analysis of brain tissue was necessary in order to assess the precision of the quantitative measurement for each protein. This guarantees a more accurate interpretation of the data.

\section{LC-MS $^{\mathrm{E}}$ Analysis of MAM Rat Frontal Cortex and Hippocampus}

Analysis of fractions 1 and 2 of frontal cortex from MAM rats by LC-MS ${ }^{\mathrm{E}}$ resulted in identification of 743 proteins (data not shown). None of these proteins showed significant differences in expression between the MAM and sham rats $(q>0.99)$. LC-MS ${ }^{\mathrm{E}}$ analysis of hippocampus from MAM rats resulted in identification of 673 proteins (data not shown), and 38 of these showed statistically significant differences in expression $(p<0.05, q<0.5$; Table 1$)$. After controlling for multiple hypotheses testing, six proteins (AMPA1, ARP3, MARCKS, HPCA, PMCA1, and SYNJ1) showed FDR qvalues of less than 0.05 . The protein expression differences ranged between 6 and 25\%, and could be measured with an average RSD of $7 \%$. This low variability of the protein abundance (Figure 1a) provides confidence in the detection of subtle expression differences such as seen here, and thereby provides greater reliability of the candidate proteins.

\section{Validation of LC-MS ${ }^{\mathrm{E}}$ Hippocampal Candidate Proteins by Immunoblot Analysis}

Six candidate proteins, showing the greatest significance after controlling for FDR $(q<0.05)$, were selected for validation. Owing to a lack of commercially available immunoassays for these proteins, we tested the candidate proteins using immunoblot analysis, which is considered to be a semiquantitative method (Mann, 2008). We used an infrared fluorescence detection system improving quantification (Schutz-Geschwender et al, 2004) and were able to confirm the altered expression of PMCA1, HPCA, and MARCKS $(p<0.05$; MAM, $n=8$; sham, $n=8)$ despite expression differences of only 7-21\% (Figure 2a and b). We could not confirm expression differences for ARP3 and SYNJ1, most likely as these showed only $7-11 \%$ changes based on the LC-MS ${ }^{\mathrm{E}}$ analysis. Interestingly, AMPA1 immunoblots of fraction 2 identified two bands. Further immunoblot experiments (Figure 2c) showed that the predicted $95 \mathrm{kDa}$ band corresponds to the non-phosphorylated form of the protein, while the upper band represents a phosphorylated form (at Serine-845/Serine-838 (Mammen et al, 1997)). Neither of these bands was expressed at significantly different levels. However, the ratio between the upper and lower band did show a significant difference between MAM and sham rats $(p=0.014)$, suggesting a potential reduced level of phosphorylated AMPA1 receptor in MAM rats. Comparison of the measurements of each protein by LC-MS ${ }^{\mathrm{E}}$ and immunoblot analysis showed significant correlations for PMCA1, HPCA, and the upper AMPA1 band (Figure 2b).

\section{In Silico Pathway Analysis of Differentially Expressed Hippocampal Proteins}

We used the IPKB software for in silico characterization of the 38 differentially expressed hippocampal proteins $(p<0.05, q<0.5$; Table 1). The SwissProt accession number of each protein was uploaded into the software, and these were mapped onto the predefined IPKB global network. Global pathway analysis of all 38 differentially expressed 
Table I Differentially Expressed Candidate Proteins in Hippocampal Tissue Derived From MAM and Sham Rats

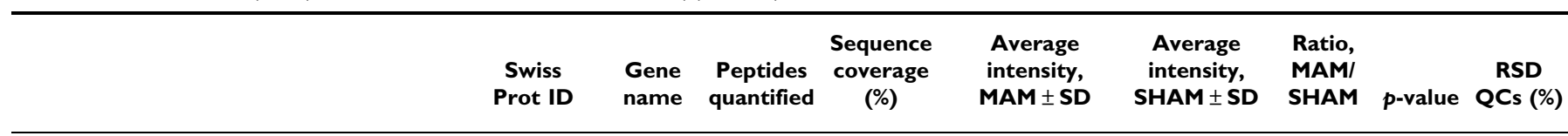

(a)

\section{Protein fraction I}

Guanine deaminase

Hippocalcin

Lactate dehydrogenase $\mathrm{A}$

Myristoylated alanine-rich protein kinase-C substrate

$\begin{array}{ccc}\text { Q9WT16 } & \text { GDA } & 41 \\ \text { P84076 } & \text { HPCA } & 21 \\ \text { P04642 } & \text { LDHA } & 40 \\ \text { P30009 } & \text { MARCKS } & 13\end{array}$

76
86
89
60

$31338 \pm 1839$
$49947 \pm 4522$
$85713 \pm 5698$
$24461 \pm 1511$

$28491 \pm 1490$

$62606 \pm 2655$

$94515 \pm 6680$

$19924 \pm 2094$

$\begin{array}{lll}1.09 & 0.0027 & 1 \\ 0.80 & 0.0000 & 8 \\ 0.91 & 0.0058 & 3 \\ 1.21 & 0.0001 & 2\end{array}$

(b)

\section{Protein fraction 2}

Amphiphysin

ARP3 actin-related protein 3

ATPase, $\mathrm{Ca}++$ transporting, plasma membrane I

ATPase, $\mathrm{Na}+/ \mathrm{K}+$ transporting

Basigin

Calcium channel, voltage-dependent, $\gamma$-subunit 8

Calcium/calmodulin-dependent protein kinase $\| \alpha$

Calcium/calmodulin-dependent protein kinase $\| \delta$

Calcium/calmodulin-dependent protein kinase $\| \gamma$

Calmodulin

Capping protein (actin filament) muscle Z-line, $\alpha 2$

Dipeptidyl-peptidase 6

Dynamin 1

FK506 binding protein IA, $12 \mathrm{kDa}$

Glial high-affinity glutamate transporter member 3

Glutamate receptor, ionotropic, and AMPA-I

Glutamate receptor, ionotropic, and AMPA 2

Glutaminase

Hemoglobin, $\beta$

Hippocalcin

Hydroxyprostaglandin dehydrogenase I5-(NAD)

Limbic system-associated membrane protein

Myosin, heavy chain 4

Myristoylated alanine-rich protein kinase-C

substrate

Neural cell-adhesion molecule I

Peroxiredoxin 6

Protein phosphatase 2, catalytic subunit, aisoform

Protein phosphatase 3, catalytic subunit, aisoform

RAB 14

RAB3C

RAB8B

Solute carrier family 4 , sodium bicarbonate

cotransporter, member 4

Synaptic vesicle glycoprotein 2B

Synaptojanin I

Tubulin, $\alpha 8$

Tubulin, $\beta 2 \mathrm{~B}$

\begin{tabular}{|c|c|c|}
\hline О08838 & AMPH & 22 \\
\hline Q4V7C7 & ACTR3 & 25 \\
\hline PII505 & PMCAI & 69 \\
\hline P06685 & ATPIAI & 60 \\
\hline P26453 & BSG & 8 \\
\hline Q8VHW5 & CACNG8 & 3 \\
\hline PII 275 & CAMK2A & 31 \\
\hline PI579| & CAMK2D & 17 \\
\hline PII730 & CAMK2G & 17 \\
\hline P62I6I & CAM & 17 \\
\hline Q3TIK5 & CAPZA2 & 8 \\
\hline P46101 & DPP6 & 13 \\
\hline P2। 575 & DNMI & 73 \\
\hline Q62658 & FKBPIA & 7 \\
\hline P24942 & SLCIA3 & 21 \\
\hline PI9490 & AMPA I & 27 \\
\hline PI949I & AMPA2 & 52 \\
\hline PI 3264 & GLS & 46 \\
\hline P0209| & $H B B$ & 15 \\
\hline P84076 & HPCA & 15 \\
\hline О08699 & HPGD & 5 \\
\hline Q62813 & LSAMP & 4 \\
\hline Q29RWI & MYH4 & 27 \\
\hline P30009 & MARCKS & 16 \\
\hline PI3596 & NCAMI & 46 \\
\hline$\bigcirc 35244$ & $P R D \times 6$ & 20 \\
\hline P6333I & PPP2CA & 3 \\
\hline P63329 & PPP3CA & 31 \\
\hline P6। I 07 & $R A B / 4$ & 23 \\
\hline P62824 & RAB3C & 12 \\
\hline P70550 & $R A B 8 B$ & 7 \\
\hline Q9J166 & SLC4A4 & 18 \\
\hline Q63564 & $S V 2 B$ & 3 \\
\hline Q62910 & SYNJI & 33 \\
\hline Q6AY56 & TUBA 8 & 12 \\
\hline Q3KRE8 & TUBB2B & 4 \\
\hline
\end{tabular}

\begin{tabular}{|c|c|c|c|}
\hline $19898 \pm 1111$ & $21274 \pm 1369$ & 0.94 & 0.0244 \\
\hline $24523 \pm 837$ & $27415 \pm 1753$ & 0.89 & 0.0003 \\
\hline $26650 \pm 990$ & $31272 \pm 1463$ & 0.85 & 0.0000 \\
\hline $81921 \pm 4513$ & $77393 \pm 4361$ & 1.06 & 0.0342 \\
\hline $10443 \pm 1056$ & $12180 \pm 830$ & 0.86 & 0.0014 \\
\hline $20737 \pm 2923$ & $24053 \pm 2917$ & 0.86 & 0.0188 \\
\hline $07485 \pm 10925$ & $127287 \pm 11068$ & 0.84 & 0.0010 \\
\hline $18553 \pm 1273$ & $20051 \pm 1139$ & 0.93 & 0.0138 \\
\hline $12968 \pm 670$ & $11998 \pm 695$ & 1.08 & 0.0058 \\
\hline $97711 \pm 12227$ & $109183 \pm 6598$ & 0.89 & 0.0257 \\
\hline $16601 \pm 837$ & $18153 \pm 1505$ & 0.91 & 0.0124 \\
\hline $16133 \pm 770$ & $17054 \pm 722$ & 0.95 & 0.0118 \\
\hline $37638 \pm 1047$ & $39025 \pm 1555$ & 0.96 & 0.0313 \\
\hline $30458 \pm 3165$ & $36348 \pm 2870$ & 0.84 & 0.0009 \\
\hline $6|487 \pm 381|$ & $57770 \pm 3472$ & 1.06 & 0.0335 \\
\hline $14177 \pm 870$ & $15 w 938 \pm 659$ & 0.89 & 0.0001 \\
\hline $13719 \pm 588$ & $14760 \pm 888$ & 0.93 & 0.0064 \\
\hline $22286 \pm 1140$ & $24418 \pm 1362$ & 0.91 & 0.0013 \\
\hline $87376 \pm 20210$ & $69534 \pm 12326$ & 1.26 & 0.0217 \\
\hline $32618 \pm 2910$ & $38319 \pm 2639$ & 0.85 & 0.0003 \\
\hline$|42| 4 \pm 853$ & $15848 \pm 1917$ & 0.90 & 0.0354 \\
\hline $11014 \pm 1105$ & $12013 \pm 659$ & 0.92 & 0.0231 \\
\hline $16105 \pm 510$ & $16803 \pm 555$ & 0.96 & 0.0093 \\
\hline $18180 \pm 954$ & $14564 \pm 3383$ & 1.25 & 0.0218 \\
\hline $33399 \pm 1662$ & $30806 \pm|66|$ & 1.08 & 0.0029 \\
\hline $22516 \pm 1223$ & $20572 \pm 2199$ & 1.09 & 0.0294 \\
\hline $4523 \pm 815$ & $5932 \pm 1049$ & 0.76 & 0.0033 \\
\hline $37842 \pm 1688$ & $41973 \pm 3455$ & 0.90 & 0.0042 \\
\hline $19017 \pm 1391$ & $20|6| \pm 707$ & 0.94 & 0.0382 \\
\hline $40694 \pm 3487$ & $36178 \pm 3076$ & 1.12 & 0.0076 \\
\hline $11284 \pm 837$ & $10442 \pm 85 \mid$ & 1.08 & 0.0393 \\
\hline $11815 \pm 832$ & $11013 \pm 650$ & 1.07 & 0.0286 \\
\hline $11568 \pm 1315$ & $13008 \pm 1322$ & 0.89 & 0.0261 \\
\hline $26469 \pm 1194$ & $29115 \pm 1604$ & 0.91 & 0.0006 \\
\hline$|4945 \pm 222|$ & $17439 \pm 1984$ & 0.86 & 0.0268 \\
\hline $22304 \pm 1794$ & $20001 \pm 2580$ & 1.12 & 0.0331 \\
\hline
\end{tabular}

The proteins in (a) fraction I (I0 MAM and 10 sham rats) and (b) fraction 2 ( 10 MAM and 10 sham rats) indicating averaged protein intensities (rounded to integers) and the standard deviation (SD), MAM/sham protein abundance ratios, $p$-values and relative standard deviation (RSD) for the measurement of each protein (determined by analysis of five quality controls that have been prepared and analyzed with the MAM and sham samples). 
a

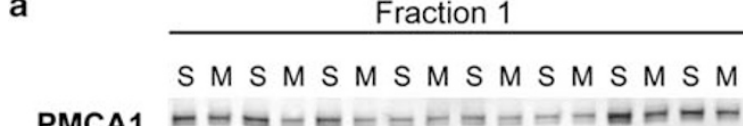

Fraction 2

S M S M S M S M S M S M S M S M

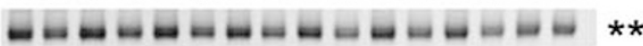

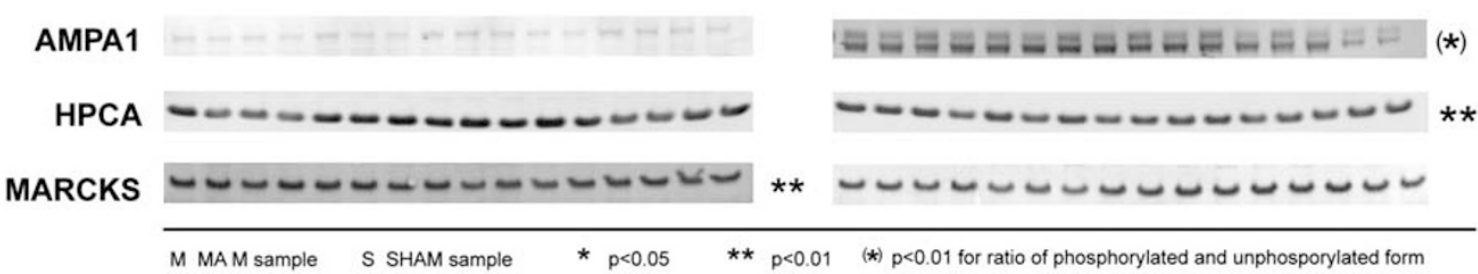

b

LC-M S

\begin{tabular}{|c|c|c|c|c|c|c|c|c|c|}
\hline \multirow[t]{2}{*}{ PROTEIN } & \multicolumn{2}{|c|}{ Fraction 1} & \multicolumn{2}{|c|}{ Fraction 2} & \multicolumn{2}{|c|}{ Fraction 1} & \multicolumn{2}{|c|}{ Fraction 2} & \multirow[b]{2}{*}{$\begin{array}{l}\text { Correlation } \\
\text { LC.M S/WB }\end{array}$} \\
\hline & $\begin{array}{c}\text { Ratio } \\
\text { M AM /SHAM }\end{array}$ & p-value & $\begin{array}{c}\text { Ratio } \\
\text { M AM /SHAI }\end{array}$ & & $\begin{array}{c}\text { Ratio } \\
\text { M AM / SHAM }\end{array}$ & $p$-value & $\begin{array}{c}\text { Ratio } \\
\text { M AM / SHAM }\end{array}$ & & \\
\hline PMCA1 & 0.86 & 0.292 & 0.86 & $2.17 \times 10^{-7}$ & 0.68 & 0.107 & 0.75 & 0.006 & $0.7^{* *}$ \\
\hline AMPA1 & - & . & 0.93 & $1.46 \times 10^{-4}$ & - & - & $0.90 \mid 1.00$ & $0.108 \mid 0.99$ & $0.46 \mid 0.21^{*}$ \\
\hline ARP3 & 1.04 & 0.410 & 0.89 & $3.00 \times 10^{-4}$ & 0.99 & 0.930 & 0.92 & 0.313 & 0.37 \\
\hline HPCA & 0.81 & $5.76 \times 10^{-6}$ & 0.85 & $3.27 \times 10^{-4}$ & 0.86 & 0.275 & 0.87 & 0.009 & $0.63^{*}$ \\
\hline SYNJ1 & - & - & 0.93 & $5.51 \times 10^{-4}$ & 1.05 & 0.688 & 0.94 & 0.743 & 0.08 \\
\hline M ARCKS & 1.21 & $1.44 \times 10^{-4}$ & 1.18 & $2.18 \times 10^{-4}$ & 1.13 & 0.006 & 1.05 & 0.691 & 0.39 \\
\hline
\end{tabular}

'Spearman correlation coeffic ent of LC-MSE and immunoblot measurements, significance of correlation is indicated as ${ }^{*} p<0.01{ }^{\circ} p<0.05$

C

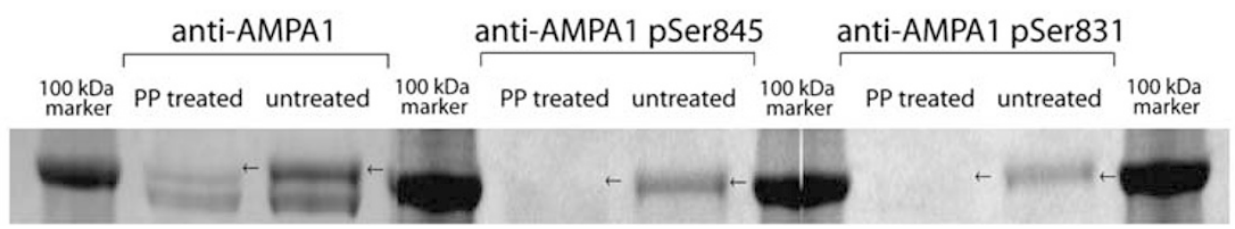

Figure 2 Immunoblot analysis of differentially expressed hippocampal candidate proteins identified by LC-MS . (a) Western blot images of candidate proteins identified in fractions $\mathrm{I}$ and 2. MAM and sham samples were loaded alternately to reduce any potential artifactual effects of differential electrotransfer. (b) Expression ratios and $p$-values are listed for each fraction. Correlation values are given for the LC-MS ${ }^{\mathrm{E}}$ and immunoblot signals. (c) Immunoblot characterization of the two AMPAI receptor bands in rat hippocampal tissue of fraction 2. Anti-AMPAI receptor immunoblot analysis of MAM and sham hippocampus shows the predicted $95 \mathrm{kDa}$ band and an additional band at $\sim 110 \mathrm{kDa}$ (indicated by $\leftarrow$ ). Phosphatase treated (protein phosphatase treated) and untreated samples were tested by western blot analysis with phospo-specific AMPAI antibodies, demonstrating that the I I $0 \mathrm{kDa}$ band is reduced in intensity after dephosphorylation. These results indicated that the $\sim 110 \mathrm{kDa}$ band is a phosphorylated form of the AMPAI receptor. Lanes I, 4, 7, and 10 show the position of a 100-kDa protein marker.

hippocampal proteins $(p<0.05, q<0.5$; Table 1$)$ showed that the most significant function associated with the altered proteins were related to cell-to-cell signaling and neuronal function ( $n=23$ proteins, associated with function, Figure 3a). At the level of canonical pathways, the three most significant associations with the 38 differentially expressed proteins $(p<0.05, q<0.5$; Table 1$)$ were calcium signaling $(n=8$ proteins, Fisher's exact test $p$-value $=$ $\left.9.34 \times 10^{-9}\right)$, synaptic long-term potentiation $(n=6$ proteins, Fisher's exact test $p$-value $\left.=2.65 \times 10^{-7}\right)$, and glutamate receptor signaling $(n=4$ proteins, Fisher's exact test $p$-value $=1.19 \times 10^{-5}$ ) (Figure $3 \mathrm{~b}$ ). The proteins assigned to these pathways are subsets of the functional network previously identified by functional analysis (Figure $3 a$ and $b)$.

Furthermore, the IPKB software detected significant molecular interaction of 22 of the 38 differentially expressed hippocampal proteins $(p<0.05, q<0.5$; Table 1$)$ using network analysis (Fisher's exact test $p$-value $=1 \times 10^{-53}$, Figure 3c). Proteins of the network are involved in nervous system development and function. Ten of the network proteins (AMPH, ATP1A1, CAMK2A, CAMK2D, AMPA1, AMPA2, NCAM1, PPP3CA, SYNJ1, and TUBA8) have been associated previously with psychological disorders, such as bipolar affective disorder ( $n=8$ proteins), schizophrenia ( $n=6$ proteins), and major depressive disorder $(n=4$ proteins; see IPKB database for further details).

\section{Cluster Analysis of Differentially Expressed Proteins in the MAM Rat Hippocampus}

We next attempted to identify clusters of co-behaving proteins among the 38 significantly altered proteins $(p<0.05, q<0.5$; Table 1), which contribute most to the differences observed in the hippocampus between MAM and sham rats. co-behavior was examined by TAC analysis (Cheng et al, 2010), as described in the methods. This led to the identification of four clusters of proteins in fraction 2, which gave $100 \%$ precision for correct classification of MAM and sham hippocampi after iterative testing (precision was defined as the proportion of MAM samples predicted correctly). The proteins forming the four 


\section{a FUNCTIONAL ANALYSIS}

\begin{tabular}{|c|c|}
\hline $\begin{array}{l}\text { Predom inantly processes of synaptic transm is sion and } \\
\text { plasticity } \\
\text { Significance of functional as sociations: } \\
\text { Fisher's exact test } p=4.05 \times 10^{-7}-4.47 \times 10^{-2}\end{array}$ & $\begin{array}{l}\text { Actin-related protein } 3 \text { (ACTR3), am phiphys in (AMPH), Na+/K+ } \\
\text { transporting ATPase (ATP1A1), Ca2+ transporting ATPase (PMCA1) } \\
\text { basigin (BSG), voltage-dependent calcium channel (CACNG8), } \\
\text { calcium /calm odulin-dependent protein kinases (CAMK2A, CAMK2D, } \\
\text { CAMK2G), dynam in } 1 \text { (DNM1), FK506 binding prote in 1A (FKBP1A), } \\
\text { glutam inase (GLS), glutamate receptors AMPA (AMPA1, AMPA2), } \\
\text { myosin (MYH4), neural cell adhesion molecule } 1 \text { (NCAM1), prote in } \\
\text { phosphatase } 3 \text { (PPP3CA), peroxiredoxin } 6 \text { (PRDX6), RAB14 protein } \\
\text { (RAB14), glial high affinity glutam ate transporter (SLC1A3), synaptic } \\
\text { vesicle glycoprote in 2B (SV2B), synaptojanin } 1 \text { (SYNJ1), tubulin } \\
\text { (TUBA8) }\end{array}$ \\
\hline
\end{tabular}

\section{b PATHWAY ANALYSIS}

\begin{tabular}{ll}
\hline CALCIUM SIGNALING & AMPA1, AMPA2, CAMK2A, CAMK2D, CAMK2G, PMCA1, MYH4, PPP3CA \\
$\begin{array}{l}\text { Fis her's exact test Fis her's exact test } p=9.34 \times 10^{-9} \\
\text { LONG TERM POTENTIATION }\end{array}$ & AMPA1, AMPA2, CAMK2A, CAMK2D, CAMK2G, PPP3CA \\
$\begin{array}{l}\text { Fisher's exact test Fis her's exact test } p=2.65 \times 10^{-7} \\
\text { GLUTAMATE RECEPTOR SIGNALING }\end{array}$ & GLS, AMPA1, AMPA2, MYH4, PPP3CA, SLC1A3 \\
Fisher's exact test Fis her's exact test $p=1.19 \times 10^{-5}$ & \\
\hline
\end{tabular}

\section{NETWORK ANALYSIS}

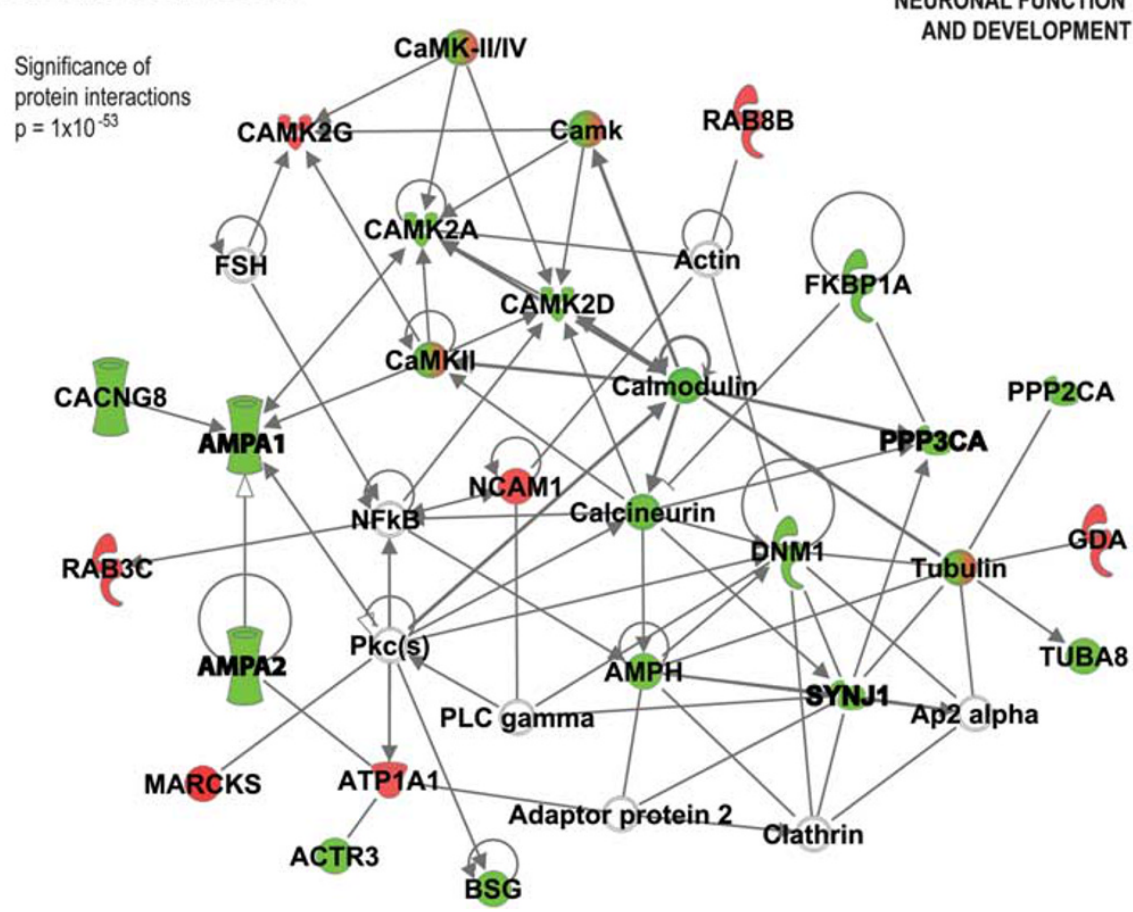

Figure 3 In silico functional, pathway and network analysis of the 38 differentially expressed candidate proteins in the hippocampus of MAM rats ( $p<0.05$, $q<0.5$; Table I): The differentially expressed proteins were overlaid onto predefined functional networks and pathways of the IPKB database. Significance of the association with a function and pathway, or protein interaction was calculated using Fisher's exact test. (a) The table lists the proteins sharing the most significant function. Proteins in bold font are part of a protein cluster identified by TAC analysis. (b) The three most significant pathways identified are listed with the associated proteins. (c) Overall, 22 of the 38 proteins are connected in an interaction network. Green = MAM/sham expression ratio $<1$, red $=$ MAM/sham expression ratio $>I$, and mixed colors = subunits/isoforms differentially expressed. Non-colored symbols = not significant in LC-MS ${ }^{E}$ analysis, although incorporated as an interacting protein by the IPKB software.

clusters (\#1 (AMPA2 + PPP3CA + SYNJ1), \#2 (AMPA1 + AMPA2 + PPP3CA), \#3 (AMPA1 + PMCA1 + PPP3CA), and \#4 (AMPA1 + AMPA2 + HPCA1)) have been previously mapped to cell-cell signaling and neuronal function by functional analysis using IPKB (Figure 3a). Interestingly, the clusters describe proteins involved in calcium and glutamate receptor signaling, as previously identified using IPKB (Figure 3b). This highlighted the importance of these pathways for the hippocampal pathology in the MAM-E17 model, as each of these clusters predicted MAM-E17 and sham rats correctly based only on the expression patterns of the three cluster proteins.

\section{${ }^{1}$ H-NMR Spectroscopic Analysis}

To study the effect of MAM treatment on the brain metabolites, ${ }^{1} \mathrm{H}-\mathrm{NMR}$ spectra were acquired for frontal cortex, hippocampus, striatum, and cerebellum. The PLSDA analysis indicated differences in the metabolic profiles of the hippocampus $\left(Q^{2}(\mathrm{cum})=0.62\right.$, Figure $\left.4 \mathrm{a}\right)$. No 


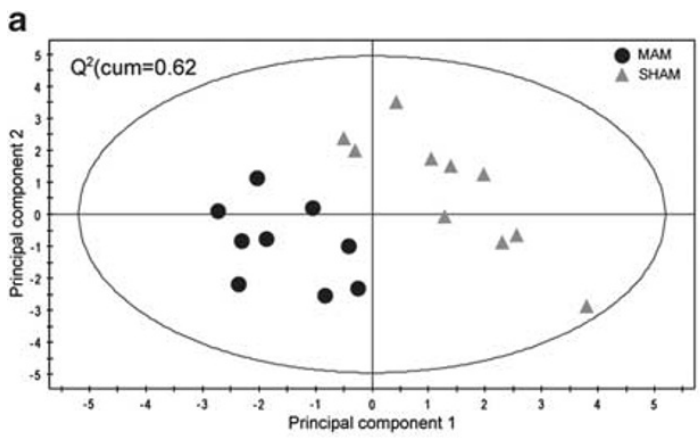

b
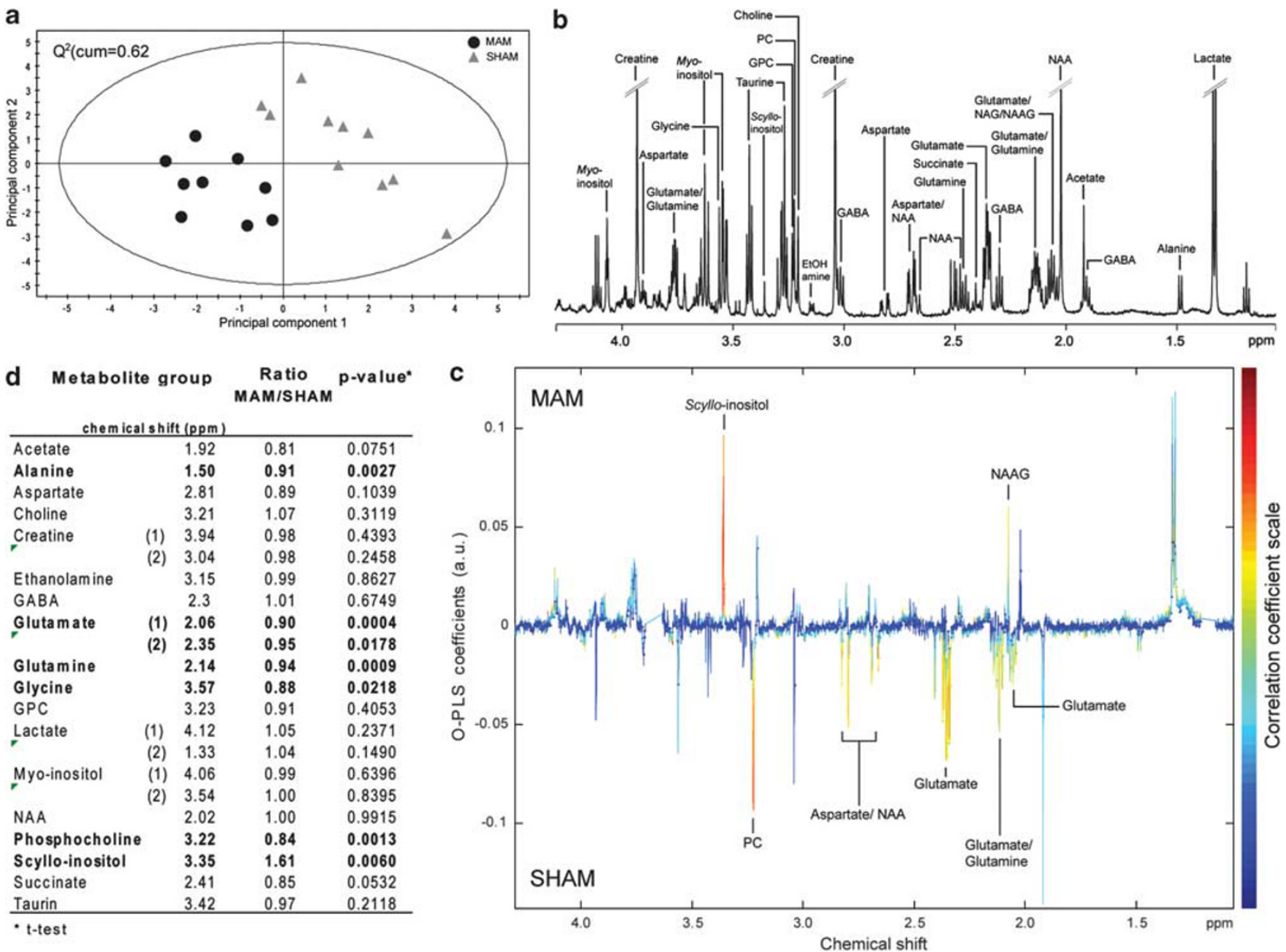

\begin{tabular}{|c|c|c|c|c|}
\hline Acetate & & 1.92 & 0.81 & 0.0751 \\
\hline Alanine & & 1.50 & 0.91 & 0.0027 \\
\hline Aspartate & & 2.81 & 0.89 & 0.1039 \\
\hline Choline & & 3.21 & 1.07 & 0.3119 \\
\hline \multirow{2}{*}{ Creatine } & (1) & 3.94 & 0.98 & 0.4393 \\
\hline & (2) & 3.04 & 0.98 & 0.2458 \\
\hline Ethanolamine & & 3.15 & 0.99 & 0.8627 \\
\hline GABA & & 2.3 & 1.01 & 0.6749 \\
\hline \multirow[t]{2}{*}{ Gluta $m$ ate } & (1) & 2.06 & 0.90 & 0.0004 \\
\hline & (2) & 2.35 & 0.95 & 0.0178 \\
\hline Glutamine & & 2.14 & 0.94 & 0.0009 \\
\hline Glycine & & 3.57 & 0.88 & 0.0218 \\
\hline GPC & & 3.23 & 0.91 & 0.4053 \\
\hline \multirow[t]{2}{*}{ Lactate } & (1) & 4.12 & 1.05 & 0.2371 \\
\hline & (2) & 1.33 & 1.04 & 0.1490 \\
\hline \multirow[t]{2}{*}{ Myo-inositol } & (1) & 4.06 & 0.99 & 0.6396 \\
\hline & (2) & 3.54 & 1.00 & 0.8395 \\
\hline NAA & & 2.02 & 1.00 & 0.9915 \\
\hline Phosphocholine & & 3.22 & 0.84 & 0.0013 \\
\hline Scyllo-inositol & & 3.35 & 1.61 & 0.0060 \\
\hline Succinate & & 2.41 & 0.85 & 0.0532 \\
\hline Taurin & & 3.42 & 0.97 & 0.2118 \\
\hline
\end{tabular}

Figure 4 Multivariate and univariate analysis of full-resolution 'H-NMR spectral data of MAM and sham hippocampi. (a) The scores plot of the PLS-DA model shows a sharp separation between MAM and the sham group $\left(Q^{2}=0.62\right)$. (b) Representative sample spectrum of a sham rat. The partially overlaying resonance regions of the 20 identified metabolites are indicated. (c) The coefficients plot of the OPLS-DA analysis indicates significantly different metabolic profiles for MAM and sham animals $\left(Q^{2}=0.35\right.$ ). Labeled spectral regions show metabolites contributing to the difference between the two groups. The direction of the peak indicates the direction of metabolite level differences (up = higher measurements in MAM rats, down = higher measurements in sham rats). The importance of the contribution to the difference between the groups is color-coded according to the correlation coefficient heat map (red = high contribution, dark blue = low contribution). (d) Univariate analysis of manually integrated 'H-NMR spectral data. The table presents the non-overlapping metabolic resonance groups and the ratio of the signal means of MAM and sham rats. Analytes with a significant difference $(p<0.05)$ of the integrated signal are highlighted.

statistically robust PLS-DA model could be constructed for the other brain regions. A representative and annotated spectrum of a sham animal is presented in Figure 4b. OPLSDA analysis was conducted to identify the metabolites responsible for the differences between MAM and sham hippocampi. The coefficients plot of the model indicated disparities in the spectral regions of scyllo-inositol, phosphocholine, glutamate, $\mathrm{N}$-acetyl aspartyl glutamate (NAAG), overlapping spectral regions of $\mathrm{N}$-acetyl aspartate (NAA)/ aspartate and glutamate/glutamine (Figure 4c). Manual integration of spectra was conducted to verify and quantify the differences found by multivariate analysis (Figure $4 \mathrm{~d}$ ). Only spectral regions showing resonances of single metabolites were considered. The metabolic profile changes seen in the OPLS-DA model were confirmed with exception of the aspartate/NAA signal. These analytes showed signal changes only in an overlapping region of the spectrum. Confirmation of the difference in NAAG levels identified by multivariate statistics was not possible, as other metabolites interfere with the signal of all NAAG resonance groups. However, the integration of the alanine and the glycine region showed significantly lower levels in MAM compared with sham rats.

Pathway analysis of the metabolites responsible for the differences between MAM and sham showed that glutamate receptor signaling was the most significant canonical pathway affected $(p=0.000002)$. Furthermore, enzymes and transporters of the glutamate-glutamine cycle, which were found to be changed in the $\mathrm{LC}-\mathrm{MS}^{\mathrm{E}}$ analysis, are known to facilitate interconversion of glutamate and glutamine in astrocytes and neurons. In addition, many significantly changed metabolites seem to be connected in an interaction network. Neuropeptide and NMDA receptor antagonist NAAG is cleaved by neuropeptidase glutamate carboxypeptidase II (GCPII) to NAA and glutamate (Slusher et al, 1990), and NMDA agonists glycine, alanine, and glutamine can be reversibly converted by transaminase reactions. 
a

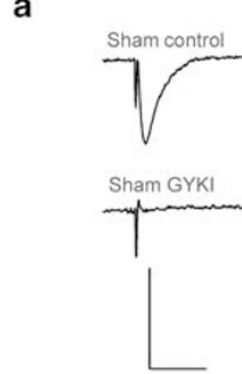

C
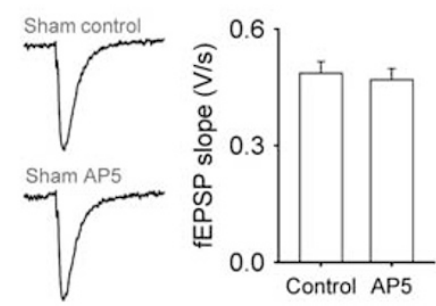

e
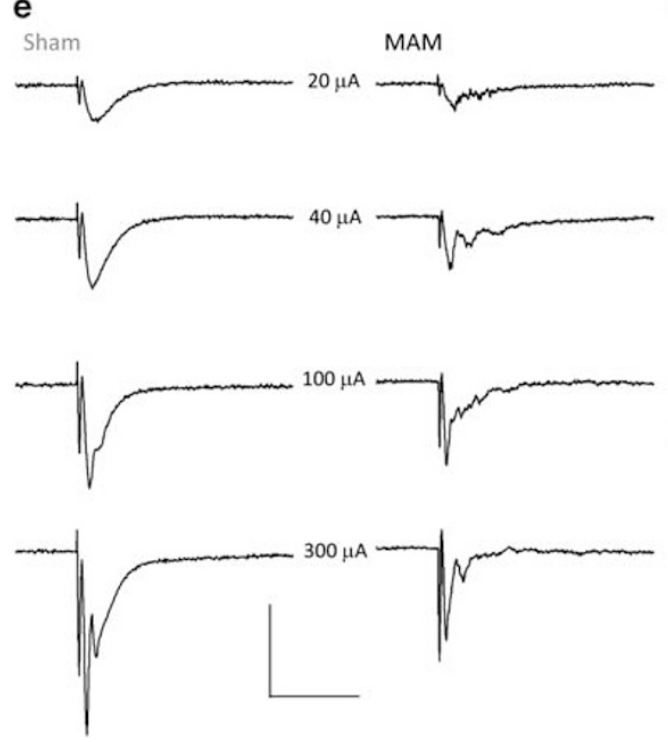

b

d

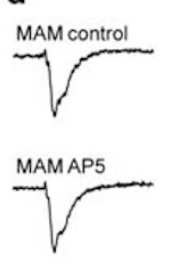

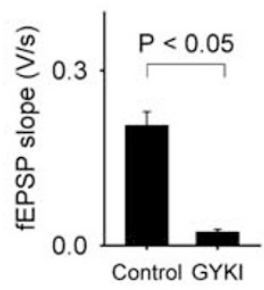

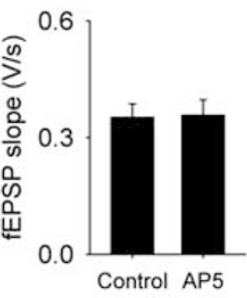

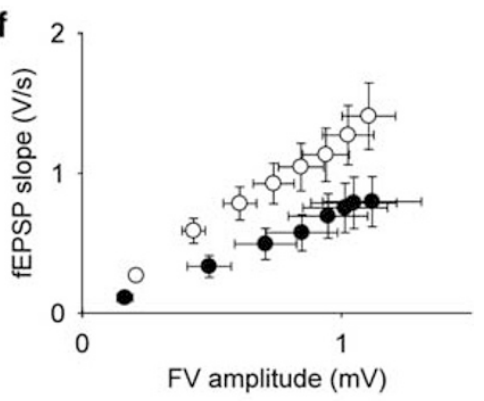

g

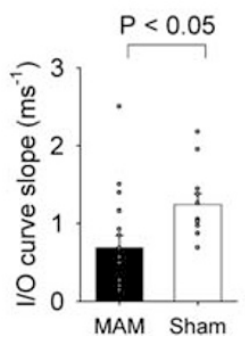

Figure 5 MAM treatment on EI7 resulted in reduced synaptic transmission in transverse hippocampal slices. (a) fEPSPs in sham slices are blocked by GYKI53784. (b) fEPSPs in MAM slices are blocked by GYKI53784. (c) fEPSPs in sham slices are unaffected by AP5. (d) fEPSPs in MAM slices are unaffected by AP5. Scale bar for (a) and (c, sham traces) represents $0.5 \mathrm{mV}$ and $20 \mathrm{~ms}$. Scale bar for (b) and (d, MAM traces) represents $0.3 \mathrm{mV}$ and $20 \mathrm{~ms}$. (e) Example traces at increasing stimulation strengths showing FVs (the first fast peak) and fEPSPs (the second slow peak). Scale bars represent I mV and $20 \mathrm{~ms}$. (f) Comparison of the FV and the fEPSP in MAM (filled points) and sham (open points) hippocampal slices. (g) Linear regression analysis of input-output relation from Figure $5 f$.

\section{Electrophysiological Analysis of MAM Rat Hippocampal Slices}

The proteomic and metabonomic results indicated changes of molecules involved in neuronal transmission in the hippocampus of MAM-E17 rats. In particular, proteins and metabolites of the glutamate receptor signaling pathway, as identified by in silico pathway and TAC analysis, seem to be affected in both studies. To test this, we investigated glutamatergic synaptic transmission using electrophysiological recordings in the CA1 area of the hippocampus. Previous studies have shown that synaptic transmission in this area is mediated by AMPA receptors (Andreasen et al, 1989; Davies and Collingridge, 1989). To investigate if
AMPA receptor changes alter excitatory synaptic function in MAM rats, synaptic transmission was investigated. In order to confirm that synaptic transmission is mediated by AMPA receptors in our preparation, the AMPA receptor antagonist GYKI53784 $(10 \mu \mathrm{M})$ was applied and found to block synaptic transmission in both sham and MAM slices. Average fEPSPs in sham slices were $0.04 \pm 0.01$ and $0.30 \pm 0.04 \mathrm{~V} / \mathrm{s}$ in the presence and absence of GYKI53784, respectively (Figure $5 \mathrm{a}, p<0.05$ ). Average fEPSPs in MAM slices were $0.02 \pm 0.01$ and $0.21 \pm 0.02 \mathrm{~V} / \mathrm{s}$ in the presence and absence of GYKI53784, respectively (Figure 5b, $p<0.05)$. Conversely, the NMDA receptor antagonist AP5 $(50 \mu \mathrm{M})$ did not affect synaptic transmission in either sham or MAM slices. Average fEPSPs in sham slices were 
$0.47 \pm 0.03$ and $0.49 \pm 0.03 \mathrm{~V} / \mathrm{s}$ in the presence and absence of AP5, respectively (Figure $5 c, p>0.05$ ). Average fEPSPs in MAM slices were $0.36 \pm 0.04$ and $0.35 \pm 0.03 \mathrm{~V} / \mathrm{s}$ in the presence and absence of AP5, respectively (Figure $5 \mathrm{~d}$, $p>0.05)$. FVs and fEPSPs were then recorded at a range of stimulation strengths. Comparative analysis showed that for any given $\mathrm{FV}$, the fEPSP generated was significantly reduced in slices from MAM rats compared with those from sham rats (Figure 5e and $\mathrm{f}$ ). Quantification of the FV vs fEPSP relationship by linear regression analysis of the MAM data set gave a slope of $0.68 \pm 0.16 \mathrm{~ms}^{-1}$, compared with $1.24 \pm 0.15 \mathrm{~ms}^{-1}$ in sham slices $(p<0.05$; Figure $5 \mathrm{~g})$. This suggested a deficit in AMPA receptor-mediated synaptic transmission.

\section{DISCUSSION}

This study describes the first molecular characterization, combined with a functional validation, of the MAM-E17 rat model for schizophrenia. The combined use of two molecular profiling platforms demonstrated that MAM administration on E17 had a significant impact on protein and metabolite levels in the hippocampus. The frontal cortex did not show any significant molecular effects of prenatal MAM exposure, even though neuroanatomical changes have been reported for this brain region (Moore et al, 2006). However, previous studies have shown that the frontal cortex has milder morphological effects in response to MAM treatment compared with those reported in the hippocampus (Flagstad et al, 2004; Lodge et al, 2009a; Matricon et al, 2010; Moore et al, 2006; Penschuck et al, 2006). Therefore, it is possible that such subtle changes might not lead to detectable molecular correlates in wholetissue lysates using the current methodologies.

Many of the differentially expressed proteins and metabolites in the hippocampus appeared to be the components of an in silico-determined interaction network, suggesting significant effects of embryonic MAM treatment on neuronal signal transduction. MAM treatment may affect neurotransmission by altering the levels of specific neurotransmitters, glutamate receptor agonists/antagonists, glutamate-glutamine cycle proteins, or synaptic vesicle controlling proteins. The data showed that MAM treatment may alter synaptic neurotransmission by affecting the extent or innervation and/or post-synaptic signal-transduction mechanisms through alterations in AMPA receptor subunit expression or phosphorylation, clathrin-mediated receptor internalization, and calcium signaling, as identified by in silico pathway analysis and supported by TAC analysis. As a variety of molecules involved in neurotransmission were found to be altered, this may indicate that multiples of these possibilities might have a synergistic role. The potential functional consequences of the molecular changes identified in the hippocampus were analyzed by in vitro electrophysiology in hippocampal slices. The fEPSP recordings in slices from MAM-treated rats showed a reduction in glutamatergic synaptic transmission. In particular, they are compatible with less expression of phosphorylated AMPA1 subunits, as preliminary biochemical data showed. Phosphorylation of AMPA1 is known to have dramatic effects on both AMPA receptor trafficking and gating. Not only highly relevant synaptic plasticity events, such as long-term potentiation, long-term depression, and depotentiation, depend on AMPA1 phosphorylation, but in AMPA1 'phosphorylation-deficient' transgenic mice, specific cognitive deficits relevant to schizophrenia were also found (Lee et al, 2003). Finally, it is worth mentioning that while the recordings suggested a reduction in AMPA receptor-mediated synaptic transmission of potential post-synaptic origin, we cannot exclude at this stage that some of the functional deficits and molecular alterations could also be caused by further changes in innervation, total number of synapses formed, or functional alteration in the interplay between neurons and glia cells at synapses in the hippocampi of MAM rats (Matricon et al, 2010). Further studies to identify and confirm the molecular basis of the synaptic deficits, investigating more complex aspects of synaptic plasticity and combining morphometric and immunohistological methods, are warranted given the potential relevance of this model for schizophrenia research and drug development.

The importance of the hippocampus in the pathology of schizophrenia has been the focus of several studies. Most of the evidence derives from post-mortem or neuropsychological studies, and many of the findings are consistent with those found in the MAM-E17 model. The most reproducible effect in patients with schizophrenia appeared to be a reduction of hippocampal size (Bogerts et al, 1990; Lawrie et al, 1999; Shenton et al, 2001), which is evident in MAM rats (Featherstone et al, 2007; Moore et al, 2006). Similarly, post-mortem studies of schizophrenia patients show disarray of pyramidal cells and a decrease in parvalbumin-expressing interneurons in the hippocampus (Kovelman and Scheibel, 1984; Zhang and Reynolds, 2002), as reported for MAM rats (Flagstad et al, 2004; Moore et al, 2006; Penschuck et al, 2006). The assignment of neuropsychological deficits in mental illnesses to specific brain structures has been a controversial subject. However, there have been suggestions that the hippocampus is involved in sensorimotor gating and latent inhibition (Gothelf et al, 2000; Gray et al, 1995; Swerdlow et al, 2001), both of which are deficient in schizophrenia patients (Braff, 1993; Braff et al, 2001; Braff et al, 1992; Gray, 1998) and adult MAM rats (Flagstad et al, 2005; Le Pen et al, 2006; Lodge et al, 2009a; Moore et al, 2006).

Functional and post-mortem studies of schizophrenia patients have shown a reduced neuronal activity and altered synaptic markers in the hippocampus, implying disrupted neuronal function (Gao et al, 2000; Medoff et al, 2001; Nesvaderani et al, 2009; Tamminga et al, 1992; Tsai et al, 1995). The most consistent findings point toward a glutamatergic synaptic pathology in schizophrenia. Various studies have shown that glutamate levels, glutamate receptors, glutamate transport, and neurotransmitter vesicle molecules are altered in the hippocampus of patients with schizophrenia (Eastwood et al, 1995b; Gao et al, 2000; Harrison et al, 2003; Hemby et al, 2002; Knable et al, 2004; Tsai et al, 1995; Webster et al, 2001). Similar effects have been demonstrated in this study for MAM rats at both the molecular and functional levels, reflecting some aspects of the glutamatergic hypothesis of schizophrenia (Kim et al, 1980). Not all of the molecular changes observed in hippocampi of schizophrenia patients have been detected 
in the MAM rats (Eastwood et al, 1995a; Eastwood and Harrison, 1998; Fatemi et al, 2000), although the same pathways and cellular functions were found to be affected, as identified by in silico pathway analysis and supported by TAC analysis. Such molecular changes may result from a decreased number of total synapses, defective synaptic coupling, or a change in the neuropil formation, as suggested by Matricon et al (2010) for the MAM-E17 model and demonstrated in cases of human schizophrenia subjects (Garey, 2010).

\section{Future Directions and Conclusion}

The combined use of a proteomics approach with complementary molecular and functional studies has resulted in identification and validation of a significant effect on glutamate neurotransmission in the offspring of MAM-treated rats. Nevertheless, the origin of these changes in the hippocampus is unclear. LC-MS ${ }^{\mathrm{E}}$ profiling of whole hippocampal tissue as used here does not take into account cell morphological and subfield-specific expression differences as seen in schizophrenia studies (Benes et al, 1991; Eastwood et al, 1995b; Gao et al, 2000; Garey, 2010; Knable et al, 2004). Therefore, we suggest that future studies should investigate subcellular and subregional expression and phophorylation patterns of synaptic markers and glutamatergic indices, as identified in this study, in combination with synaptic structure and density measurements in hippocampal subfields of the MAM-E17 rat model. In addition, further investigation of the functional markers NAA (Simmons et al, 1991), aspartate, and related molecules is of interest as these have also been found to be reduced in hippocampi of schizophrenia patients (Bertolino et al, 1996; Deicken et al, 1998; Maier et al, 1995; Tsai et al, 1995). A reduction in NAA might result from reduced GCPII activity as seen in schizophrenia (Tsai et al, 1995). This enzyme is known to cleave NAAG to produce NAA and glutamate, which were both changed significantly in this study.

It is now accepted that animal models per se can recapitulate only certain aspects of neuropsychiatric disease. The present studies showed that MAM treatment of rats may lead to an altered glutamatergic neurotransmission in the hippocampus, although the exact cause of this deficit remains to be elucidated. Nevertheless, this study provides the first molecular evidence, combined with functional validation, that the MAM-E17 rat model reproduces hippocampal deficits relevant to the pathology of schizophrenia. Further investigation of these deficits using this model may lead to further insights into the hypoglutamatergic hypothesis of schizophrenia and demonstrate its potential utility for drug discovery and development.

\section{ACKNOWLEDGEMENTS}

We thank Dan Ma, Sandra Pietsch, and Christin Oheim for help with the dissection of the rat brains and immunoblots, and Yishai Levin and Emanuel Schwarz for helpful discussions. This research was supported by the IMI NEWMEDS European Framework Programme (FP7) and Stanley Medical Research Institute.

\section{DISCLOSURE}

E. Hradetzky was supported by a BBSRC CASE award jointly with Eli Lilly and Co Ltd. TM Sanderson, JL Sherwood, SM Fitzjohn, V Lakics, N Malik, MJ O’Neill, E Sher, and MD Tricklebank are full-time employees of Eli Lilly and Co Ltd and received no other financial remuneration. GL Collingridge is supported by the Medical Research Council. PC Guest and $\mathrm{H}$ Rahmoune are consultants for Psynova Neurotech. The other authors declare that no financial support or compensation has been received from any individual or corporate entity for research or professional service and there are no personal financial holdings that could be perceived as constituting a potential conflict of interest.

\section{REFERENCES}

Anderson WW, Collingridge GL (2001). The LTP Program: a data acquisition program for on-line analysis of long-term potentiation and other synaptic events. J Neurosci Methods 108: 71-83.

Andreasen M, Lambert JD, Jensen MS (1989). Effects of new non$\mathrm{N}$-methyl-D-aspartate antagonists on synaptic transmission in the in vitro rat hippocampus. J Physiol 414: 317-336.

Bayer SA, Altman J, Russo RJ, Zhang X (1993). Timetables of neurogenesis in the human brain based on experimentally determined patterns in the rat. Neurotoxicology 14: 83-144.

Benes FM, Sorensen I, Bird ED (1991). Reduced neuronal size in posterior hippocampus of schizophrenic patients. Schizophr Bull 17: 597-608.

Benjamini J, Hochberg Y (1995). Controlling the false discovery rate: a practical and powerful approach to multiple testing. J Roy Statist Soc Series B (Methodological) 57: 289-300.

Bertolino A, Nawroz S, Mattay VS, Barnett AS, Duyn JH, Moonen CT et al (1996). Regionally specific pattern of neurochemical pathology in schizophrenia as assessed by multislice proton magnetic resonance spectroscopic imaging. Am J Psychiatry 153: 1554-1563.

Bogerts B, Ashtari M, Degreef G, Alvir JM, Bilder RM, Lieberman JA (1990). Reduced temporal limbic structure volumes on magnetic resonance images in first episode schizophrenia. Psychiatry Res 35: 1-13.

Braff DL (1993). Information processing and attention dysfunctions in schizophrenia. Schizophr Bull 19: 233-259.

Braff DL, Geyer MA, Light GA, Sprock J, Perry W, Cadenhead KS et al (2001). Impact of prepulse characteristics on the detection of sensorimotor gating deficits in schizophrenia. Schizophr Res 49: 171-178.

Braff DL, Grillon C, Geyer MA (1992). Gating and habituation of the startle reflex in schizophrenic patients. Arch Gen Psychiatry 49: 206-215.

Calvano SE, Xiao W, Richards DR, Felciano RM, Baker HV, Cho RJ et al (2005). A network-based analysis of systemic inflammation in humans. Nature 437: 1032-1037.

Cattabeni F, Di Luca M (1997). Developmental models of brain dysfunctions induced by targeted cellular ablations with methylazoxymethanol. Physiol Rev 77: 199-215.

Cattaneo E, Reinach B, Caputi A, Cattabeni F, Di Luca M (1995). Selective in vitro blockade of neuroepithelial cells proliferation by methylazoxymethanol, a molecule capable of inducing long lasting functional impairments. J Neurosci Res 41: 640-647.

Cheng TM, Lu YE, Guest PC, Rahmoune H, Harris LW, Wang L et al (2010). Identification of targeted analyte clusters for studies of schizophrenia. Mol Cell Proteomics 9: 510-522.

Cloarec O, Dumas ME, Trygg J, Craig A, Barton RH, Lindon JC et al (2005). Evaluation of the orthogonal projection on latent 
structure model limitations caused by chemical shift variability and improved visualization of biomarker changes in $1 \mathrm{H}$ NMR spectroscopic metabonomic studies. Anal Chem 77: 517-526.

Davies SN, Collingridge GL (1989). Role of excitatory amino acid receptors in synaptic transmission in area CA1 of rat hippocampus. Proc $R$ Soc Lond B Biol Sci 236: 373-384.

Deicken RF, Zhou L, Schuff N, Fein G, Weiner MW (1998). Hippocampal neuronal dysfunction in schizophrenia as measured by proton magnetic resonance spectroscopy. Biol Psychiatry 43: 483-488.

Eastwood SL, Burnet PW, Harrison PJ (1995a). Altered synaptophysin expression as a marker of synaptic pathology in schizophrenia. Neuroscience 66: 309-319.

Eastwood SL, Harrison PJ (1998). Hippocampal and cortical growth-associated protein-43 messenger RNA in schizophrenia. Neuroscience 86: 437-448.

Eastwood SL, McDonald B, Burnet PW, Beckwith JP, Kerwin RW, Harrison PJ (1995b). Decreased expression of mRNAs encoding non-NMDA glutamate receptors GluR1 and GluR2 in medial temporal lobe neurons in schizophrenia. Brain Res Mol Brain Res 29: 211-223.

Eriksson L, Antti H, Gottfries J, Holmes E, Johansson E, Lindgren F et al (2004). Using chemometrics for navigating in the large data sets of genomics, proteomics, and metabonomics (gpm). Anal Bioanal Chem 380: 419-429.

Fatemi SH, Earle JA, McMenomy T (2000). Reduction in Reelin immunoreactivity in hippocampus of subjects with schizophrenia, bipolar disorder and major depression. Mol Psychiatry 5: 654-663, 571 .

Featherstone RE, Rizos Z, Nobrega JN, Kapur S, Fletcher PJ (2007). Gestational methylazoxymethanol acetate treatment impairs select cognitive functions: parallels to schizophrenia. Neuropsychopharmacology 32: 483-492.

Flagstad P, Glenthoj BY, Didriksen M (2005). Cognitive deficits caused by late gestational disruption of neurogenesis in rats: a preclinical model of schizophrenia. Neuropsychopharmacology 30: $250-260$.

Flagstad P, Mork A, Glenthoj BY, van Beek J, Michael-Titus AT, Didriksen M (2004). Disruption of neurogenesis on gestational day 17 in the rat causes behavioral changes relevant to positive and negative schizophrenia symptoms and alters amphetamineinduced dopamine release in nucleus accumbens. Neuropsychopharmacology 29: 2052-2064.

Gao XM, Sakai K, Roberts RC, Conley RR, Dean B, Tamminga CA (2000). Ionotropic glutamate receptors and expression of $\mathrm{N}$ methyl-D-aspartate receptor subunits in subregions of human hippocampus: effects of schizophrenia. Am J Psychiatry 157: 1141-1149.

Garey L (2010). When cortical development goes wrong: schizophrenia as a neurodevelopmental disease of microcircuits. J Anat 217: 324-333.

Geromanos SJ, Vissers JP, Silva JC, Dorschel CA, Li GZ, Gorenstein MV et al (2009). The detection, correlation, and comparison of peptide precursor and product ions from data independent LCMS with data dependant LC-MS/MS. Proteomics 9: 1683-1695.

Gothelf D, Soreni N, Nachman RP, Tyano S, Hiss Y, Reiner O et al (2000). Evidence for the involvement of the hippocampus in the pathophysiology of schizophrenia. Eur Neuropsychopharmacol 10: 389-395.

Gray JA (1998). Integrating schizophrenia. Schizophr Bull 24: 249-266.

Gray JA, Joseph MH, Hemsley DR, Young AM, Warburton EC, Boulenguez $\mathrm{P}$ et al (1995). The role of mesolimbic dopaminergic and retrohippocampal afferents to the nucleus accumbens in latent inhibition: implications for schizophrenia. Behav Brain Res 71: 19-31.

Hansen CF, Torgalsboen AK, Melle I, Bell MD (2009). Passive/ apathetic social withdrawal and active social avoidance in schizophrenia: difference in underlying psychological processes. J Nerv Ment Dis 197: 274-277.

Harrison PJ (1999). The neuropathology of schizophrenia. A critical review of the data and their interpretation. Brain 122(Part 4): 593-624.

Harrison PJ, Law AJ, Eastwood SL (2003). Glutamate receptors and transporters in the hippocampus in schizophrenia. Ann NY Acad Sci 1003: 94-101.

Hemby SE, Ginsberg SD, Brunk B, Arnold SE, Trojanowski JQ, Eberwine JH (2002). Gene expression profile for schizophrenia: discrete neuron transcription patterns in the entorhinal cortex. Arch Gen Psychiatry 59: 631-640.

Kim JS, Kornhuber HH, Schmid-Burgk W, Holzmuller B (1980). Low cerebrospinal fluid glutamate in schizophrenic patients and a new hypothesis on schizophrenia. Neurosci Lett 20: 379-382.

King R, Bonfiglio R, Fernandez-Metzler C, Miller-Stein C, Olah T (2000). Mechanistic investigation of ionization suppression in electrospray ionization. J Am Soc Mass Spectrom 11: 942-950.

Knable MB, Barci BM, Webster MJ, Meador-Woodruff J, Torrey EF (2004). Molecular abnormalities of the hippocampus in severe psychiatric illness: postmortem findings from the Stanley Neuropathology Consortium. Mol Psychiatry 9: 609-620, 544.

Kovelman JA, Scheibel AB (1984). A neurohistological correlate of schizophrenia. Biol Psychiatry 19: 1601-1621.

Lan MJ, McLoughlin GA, Griffin JL, Tsang TM, Huang JT, Yuan P et al (2009). Metabonomic analysis identifies molecular changes associated with the pathophysiology and drug treatment of bipolar disorder. Mol Psychiatry 14: 269-279.

Laruelle M, Abi-Dargham A, van Dyck CH, Gil R, D'Souza CD, Erdos J et al (1996). Single photon emission computerized tomography imaging of amphetamine-induced dopamine release in drug-free schizophrenic subjects. Proc Natl Acad Sci USA 93: 9235-9240.

Lawrie SM, Whalley H, Kestelman JN, Abukmeil SS, Byrne M, Hodges A et al (1999). Magnetic resonance imaging of brain in people at high risk of developing schizophrenia. Lancet 353: 30-33.

Le Pen G, Gourevitch R, Hazane F, Hoareau C, Jay TM, Krebs MO (2006). Peri-pubertal maturation after developmental disturbance: a model for psychosis onset in the rat. Neuroscience 143: 395-405.

Lee HK, Takamiya K, Han JS, Man H, Kim CH, Rumbaugh G et al (2003). Phosphorylation of the AMPA receptor GluR1 subunit is required for synaptic plasticity and retention of spatial memory. Cell 112: 631-643.

Levin Y, Schwarz E, Wang L, Leweke FM, Bahn S (2007). Label-free LC-MS/MS quantitative proteomics for large-scale biomarker discovery in complex samples. J Sep Sci 30: 2198-2203.

Li GZ, Vissers JP, Silva JC, Golick D, Gorenstein MV, Geromanos SJ (2009). Database searching and accounting of multiplexed precursor and product ion spectra from the data independent analysis of simple and complex peptide mixtures. Proteomics 9: 1696-1719.

Lodge DJ, Behrens MM, Grace AA (2009a). A loss of parvalbumincontaining interneurons is associated with diminished oscillatory activity in an animal model of schizophrenia. J Neurosci 29: 2344-2354.

Lodge DJ, Grace AA (2009b). Gestational methylazoxymethanol acetate administration: a developmental disruption model of schizophrenia. Behav Brain Res 204: 306-312.

Lubow RE, Gewirtz JC (1995). Latent inhibition in humans: data, theory, and implications for schizophrenia. Psychol Bull 117: 87-103.

Maier M, Ron MA, Barker GJ, Tofts PS (1995). Proton magnetic resonance spectroscopy: an in vivo method of estimating hippocampal neuronal depletion in schizophrenia. Psychol Med 25: $1201-1209$. 
Mammen AL, Kameyama K, Roche KW, Huganir RL (1997). Phosphorylation of the alpha-amino-3-hydroxy-5-methylisoxazole4-propionic acid receptor GluR1 subunit by calcium/ calmodulin-dependent kinase II. J Biol Chem 272: 32528-32533.

Mann M (2008). Can proteomics retire the western blot? J Proteome Res 7: 3065.

Matricon J, Bellon A, Frieling H, Kebir O, Le Pen G, Beuvon F et al (2010). Neuropathological and Reelin deficiencies in the hippocampal formation of rats exposed to MAM; differences and similarities with schizophrenia. PLoS One 5: e10291.

Medoff DR, Holcomb HH, Lahti AC, Tamminga CA (2001). Probing the human hippocampus using rCBF: contrasts in schizophrenia. Hippocampus 11: 543-550.

Meyn RE, Murray D (1984). Cell cycle effects of alkylating agents. Pharmacol Ther 24: 147-163.

Molloy MP, Brzezinski EE, Hang J, McDowell MT, VanBogelen RA (2003). Overcoming technical variation and biological variation in quantitative proteomics. Proteomics 3: 1912-1919.

Molloy MP, Donohoe S, Brzezinski EE, Kilby GW, Stevenson TI, Baker JD et al (2005). Large-scale evaluation of quantitative reproducibility and proteome coverage using acid cleavable isotope coded affinity tag mass spectrometry for proteomic profiling. Proteomics 5: 1204-1208.

Moore H, Jentsch JD, Ghajarnia M, Geyer MA, Grace AA (2006). A neurobehavioral systems analysis of adult rats exposed to methylazoxymethanol acetate on E17: implications for the neuropathology of schizophrenia. Biol Psychiatry 60: 253-264.

Nesvaderani M, Matsumoto I, Sivagnanasundaram S (2009). Anterior hippocampus in schizophrenia pathogenesis: molecular evidence from a proteome study. Aust NZ J Psychiatry 43: $310-322$.

Penschuck S, Flagstad P, Didriksen M, Leist M, Michael-Titus AT (2006). Decrease in parvalbumin-expressing neurons in the hippocampus and increased phencyclidine-induced locomotor activity in the rat methylazoxymethanol (MAM) model of schizophrenia. Eur J Neurosci 23: 279-284.
Schutz-Geschwender A, Z Y, Holt T, McDermitt D, Olive DM (2004). Quantitative, Two-Color Western Blot Detection with Infrared Fluorescence. LI-COR Biosciences http://www.licor.com/ bio/PDF/IRquant.pdf.

Shenton ME, Dickey CC, Frumin M, McCarley RW (2001). A review of MRI findings in schizophrenia. Schizophr Res 49: 1-52.

Silva JC, Denny R, Dorschel CA, Gorenstein M, Kass IJ, Li GZ et al (2005). Quantitative proteomic analysis by accurate mass retention time pairs. Anal Chem 77: 2187-2200.

Simmons ML, Frondoza CG, Coyle JT (1991). Immunocytochemical localization of $\mathrm{N}$-acetyl-aspartate with monoclonal antibodies. Neuroscience 45: 37-45.

Slusher BS, Robinson MB, Tsai G, Simmons ML, Richards SS, Coyle JT (1990). Rat brain $N$-acetylated alpha-linked acidic dipeptidase activity. Purification and immunologic characterization. J Biol Chem 265: 21297-21301.

Storey JD (2002). A direct approach to false discovery rates. $J R$ Statist Soc B 64: 479-498.

Swerdlow NR, Geyer MA, Braff DL (2001). Neural circuit regulation of prepulse inhibition of startle in the rat: current knowledge and future challenges. Psychopharmacology (Berl) 156: 194-215.

Tamminga CA, Thaker GK, Buchanan R, Kirkpatrick B, Alphs LD, Chase TN et al (1992). Limbic system abnormalities identified in schizophrenia using positron emission tomography with fluorodeoxyglucose and neocortical alterations with deficit syndrome. Arch Gen Psychiatry 49: 522-530.

Tsai G, Passani LA, Slusher BS, Carter R, Baer L, Kleinman JE et al (1995). Abnormal excitatory neurotransmitter metabolism in schizophrenic brains. Arch Gen Psychiatry 52: 829-836.

Webster MJ, Shannon Weickert C, Herman MM, Hyde TM, Kleinman JE (2001). Synaptophysin and GAP-43 mRNA levels in the hippocampus of subjects with schizophrenia. Schizophr Res 49: 89-98.

Zhang ZJ, Reynolds GP (2002). A selective decrease in the relative density of parvalbumin-immunoreactive neurons in the hippocampus in schizophrenia. Schizophr Res 55: 1-10. 